\title{
Chronic Complainers or Increased Awareness? The Dynamics of Social Media Customer Service
}

\author{
Shujing Sun \\ Naveen Jindal School of Management \\ University of Texas at Dallas \\ shujing.sun@utdallas.edu
}

\author{
Yang Gao \\ Simon Business School \\ University of Rochester \\ yang.gao@simon.rochester.edu
}

\author{
Huaxia Rui \\ Simon Business School \\ University of Rochester \\ huaxia.rui@simon.rochester.edu
}

\begin{abstract}
Despite that social media has become a promising alternative to traditional call centers, managers hesitate to fully harness its power because they worry that active service intervention may encourage excessive use of the channel by disgruntled customers. This paper sheds light on such a concern by examining the dynamics between brand-level customer complaints and service interventions on social media. Using details of customer-brand interactions of 40 airlines on Twitter, we find that more service interventions indeed cause more customer complaints, accounting for the online customer population and service quality. However, the increased complaints are primarily driven by the awareness enhancement mechanism rather than by chronic complainers. Furthermore, holding everything else fixed, high-quality care leads to fewer future complaints. The managerial implication is clear: firms shall implement a more active, prompt, and effective strategy, which can redirect customers to this cost-effective service channel and ultimately reduce customer churn.
\end{abstract}

\section{Introduction}

Business-to-consumer (B2C) firms are rediscovering social media as not merely a tool for marketing engagement but also a free platform through which they can respond to customer complaints asynchronously and cost-effectively. However, delivering customer service on social media is a delicate business, with both opportunities and potential pitfalls. According to McKinsey \& Company, the handling cost per customer on Twitter is about one-sixth of the handling cost through traditional call centers! Moreover, the proper handling of a customer's complaint can not only turn

\footnotetext{
${ }^{1}$ McKinsey \& Company reports that trained customer service agents can handle four to eight times the number of contacts received through social media as they can by phone. For more details, see https://www.mckinsey.com/business-functions
}

a service failure into a positive brand experience for that particular customer but also create a positive brand perception among other social media users who have observed the customer service interaction directly or indirectly. Such an amplification effect is a direct consequence of the public and connected nature of social media. In the meantime, the amplification effect can go the opposite way with negative word-of-mouth, which will lead to unintended consequences [1]. Compared to service successes, service failures tend to grab more attention because negative information is often considered by consumers as more informative than positive information when they form their overall evaluation of a brand [2]. Hence, customer service failures may not only result in the loss of a complaining customer but also negatively affect overall brand perceptions of those observing the failed service response. In essence, the unique features of social media amplify the impact of each customer service interaction, and the degree of amplification is likely larger for unsuccessful intervention.

Because of the high stake in delivering customer service on social media, managers naturally may wonder the proper degree of involvement in this new digital arena. However, due to the limited knowledge about brand-level customer complaints dynamics, there is no clear guidance. Currently, firms generally respond to less than half of customer complaints directed at them on Twitter [3]. Relying on Twitter data of 714 customers from a telecommunications firm, Ma et al. (2015) found that service intervention (on social media) raises customers' expectations of being helped and increases their tendencies to complain in the future [4]. Although this mechanism likely exists in all forms of customer service, it probably is more pronounced for social media customer service because of its convenience. As such, it is concerning to firms if disgruntled customers exploit social media to vent excessively or to complain just about everything, thereby making the service channel a playground for chronic complainers. The increasing volume of complaints directed at brands' social media 
accounts also seems to validate this concern at an aggregate level (see Figure 1). The objective of this paper is to shed light on these important and pressing issues faced by many managers who wish to harness the power of social media for their brands. Does an active strategy invite more customer complaints? If so, what is the underlying mechanism? Conditional on the level of service intervention, will better service encourage or avert more future complaints? By examining these research questions, we hope to better understand the interplay between customer service and customer complaints on social media, and help managers to effectively improve their social media strategy.

Our study is based on a large data set consisting of all customer service interactions between 40 major international airlines and their customers on Twitter from January 2014 to September 2019. We find that more service interventions indeed lead to more service complaints on social media. However, such an increase is not much driven by repeated complaints from chronic customers. In fact, customers in our data sample complained to an airline on Twitter only 1.4 times on average, throughout nearly six years. Rather, the causal mechanism works largely through the awareness enhancement effect of service intervention: each time a firm responds to a customer service inquiry on social media, other social media users who are exposed to the conversation become aware of this service channel and are more likely to use it in the future. Furthermore, we find evidence that higher customer service quality can actually reduce the volume of future complaints on social media. Holding everything else fixed, more prompt responses and a higher resolution rate both lead to fewer future complaints.

These findings contribute to the literature by enriching our understanding of the dynamics between service intervention and customer complaints on social media. Indeed, there is a dual role of each service intervention on social media: addressing a particular customer's complaint and increasing the awareness of the new channel among customers who are connected to the complaining customer. Since the increasing volume of customer complaints is mainly driven by service awareness, we believe firms can significantly benefit from a more active social media customer service strategy for two reasons. First, such a strategy will make more customers become aware and ultimately switch to social media for service requests. Given the much lower cost of customer service provision through social media than conventional channels, accelerated migration to social media customer service has a clear cost-saving benefit. Second, with more customers, who would otherwise not bother to contact firms via traditional call centers, start to seek support through the handy social media channel, there will be less customer defection for firms. According to Hirschman (1970)'s theory of Exit, Voice, and Loyalty [5], a customer's voicing decision is an alternative to exiting from a firm's business. Hence, providing more customers with a convenient voicing channel help retain customers and reduce future customer acquisition cost. The managerial implication from our findings is thus clear: firms have more reasons to embrace social media customer service and should be less concerned about its being abused. According to Sprout Social, the average brands' response rate is only about $10 \%$ in 2017 , which we believe is a sub-optimal strategy that results in plenty of wasted opportunities ${ }^{2}$ With increasingly more people adopting social media $3^{3}$ social media customer service will be a defining future trend. 4

\section{Literature Review}

\subsection{Evolution of Call Center}

Advancements in information technology have enabled firms to provide customer service through several alternative channels. One leading alternative is self-service technology, such as the Web-based self-service portals [6]. As a further extension of call centers, social media customer service has drawn increasing attention in recent years. Ma et al. (2015) examined the effect of service intervention on customer voices to a telecommunications firm on Twitter [4]. The paper found that redress seeking is a major driver of complaints and the firm's service intervention can actually encourage more future complaints from individual customers. From the organizational perspective, studies found evidence of firms' differential service treatment by customers' online influence [3] and politeness [7].

\subsection{Customer Complaint Management}

The first stream of literature on customer complaint management examines the motivations underlying customer voices. According to Hirschman (1970), when customers perceive deteriorated service or product

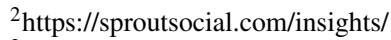

${ }^{3}$ According to the Pew Research Center, social media usage has been growing rapidly over the years. By the end of $2019,72 \%$ of U.S adults use at least one social media site. Please find more details at https://www.pewresearch.org/internet/fact-sheet/social-media/.

${ }^{4}$ The use of social media is expected to increase in the coming years as younger generations become consumers and companies become more proactive about answering messages in those channels, says Scott Broetzmann, president and chief executive of Alexandria, Va.-based Customer Care Measurement. Please find more details at https://www.wsj.com/articles.
} 
quality, they can choose to either exit from the firm's business or voice to elicit a brand response and solicit individual compensation [5]. Grounded in Hirschman's theory, following studies have shown that customers' word-of-mouth is driven by 1) intrinsic factors, such as an individual's desire for social interaction, economic incentives, self-enhancement, and concerns of others' perceptions [8, 9]; and 2) external factors, such as product characteristics [10] and brand characteristics (i.e., level of differentiation, excitement, and complexity) [11].

Our work closely relates to the nascent literature on how online managerial responses affect customer voices. Existing studies have shown that online management responses can positively affect customer satisfaction [12], hotel's star rating [13], and customers' subsequent reviews [14]. Several papers also examined brand strategies to manage online customer voices from various perspectives. For instance, Yi et al. (2019) showed that firms can effectively manage consumer-generated reviews and improve consumption by strategically highlighting positive but less extreme reviews [15]. Two recent studies devised predictive models of response strategies so that firms can better control for review ratings [16] and customer sentiment [17].

Although there is extensive literature on customer complaint management, few have investigated the dynamics between customer complaining behavior and firms' service intervention in the context of social media. The only exception is Ma et al. (2015), which examined the effect of brand service intervention on customers' subsequent compliments and complaints to a telecommunication firm on Twitter. Compared with Ma et al. (2015), this study presents several notable differences. First, while Ma et al. (2015) focused on the individual voicing decisions using a fixed sample of 714 customers, we are interested in the relationships of aggregated customer complaints and brand service interventions within a dynamic setting. The unique data set allows us to identify the evolving process of brand-level complaining behavior, accounting for the dynamic changes in customer population, service quality, online and offline shocks to a brand. Moreover, we believe that the aggregated level analysis is critical for a firm's strategy adjustment and resource allocation. Second, instead of considering the service intervention as a binary treatment, we extract multi-dimensional service strategy measures from the textual information of customer-brand conversations. The granular analysis is crucial for identification purposes since customer complaining behaviors are influenced by multiple endogenous factors, of which service quality is an important determinant. Lastly, unlike the telecommunication firm in Ma et al. (2015), airlines face a customer base most of whom do not frequently receive their service. Our findings indicate that the risk implied by Ma et al. (2015) is practically not significant in a general setting, at least not for the airline industry. We believe such knowledge has been missing in the literature and provide important insights to researchers and practitioners.

\section{Hypothesis Development}

In this section, we develop two sets of hypotheses corresponding to the service level (i.e., the number of brand service interventions to customer-initiated redress-seeking posts) and the service quality (i.e., the promptness and effectiveness of brand responses).

\subsection{Service Level and Customer Complaints}

To understand how service level might affect the aggregated complaint volume, we distinguish two groups of customers: focal customers are those who complain to firms on social media and bystanders are those who observe the service encounters between focal customers and the involved firms. As a brand response credibly signals its service availability, we argue that the brand service level can affect the volume of customer complaints in the following ways.

First, the effect of service level on a focal customer's voicing propensity can go in both directions. On the one hand, active responses signal a firm's caring about the customer, which contributes to her commitment and loyalty to the brand. With the improved customer-brand relationship and enhanced brand perception, the focal customer is less likely to publicly complain to the brand on social media in the future [18]. On the other hand, brand service interventions may incur more subsequent complaints from a focal customer, as the prior experience boosts her confidence about a firm's accountability and the likelihood of resolving problems [4]. As such, even with a static customer base, a firm may still experience an increasing trend in customer complaints as the service level increases.

Second, due to the public nature of social media, a focal customer's complaint and the associated brand service interventions are observable to bystanders. This helps increase the bystanders' awareness of the new service channel and redirect them to social media for future service requests. Blodgett et al. (1995) suggested that a primary determinant on whether a customer seeks redress is the perceived likelihood of success [19]. Even customers who would otherwise exit are more likely to seek redress if it is clear that the seller is willing to 
remedy the problem. As the service level increases, a brand essentially advertises its service availability and caring about customers, which further enhances bystanders' expectation of getting customer support through social media. Collectively, the increased service awareness may drive more customers to social media for future redress seeking. Moreover, survey data show that focal customers are more likely to share their experiences, both online and offline, after receiving a firm's response ${ }^{5}$ Such word-of-mouth generated by focal customers also facilitates the overall awareness of a brand's social media customer service.

Considering the different theoretical effects of service intervention on focal customers and bystanders, the volume of customer complaints can either increase or decrease as firms increase their service level. To examine this empirically, we propose the following hypothesis for statistical tests.

Hypothesis 1 (H1): Ceteris paribus, a higher service level (i.e., more brand interventions) will lead to more customer complaints.

\subsection{Service Quality and Customer Complaints}

Much like the conventional calls at an 800 number, customers expect quick and effective responses on social media. While customers certainly benefit from high-grade service intervention, it remains unclear how service quality influences their propensities to complain in the future. Holding everything else the same, we hypothesize that service quality can affect customer complaints through two competing mechanisms.

Anecdotal evidence implies that $31 \%$ of customers in the United States expect a response within 24 hours or less, $24 \%$ expect a response within an hour, and $20 \%$ expect to get a response immediately ${ }^{6}$ As social media enables convenient and almost instant sharing among friends, a prompt and effective response can not only turn a service failure into a positive brand experience for the complaining customer but also deliver a positive brand image to bystanders. Besides, a prompt intervention helps avoid new problems or aggravate existing ones [20]. Compared with the effect of active service responses, service quality is more likely to improve the customer-brand relationship. Accordingly, we expect that high-quality customer support can better facilitate the broadcasting of positive brand image and, as a result, more likely to reduce future complaints occurrences to a large extent.

On the other hand, given the same service level,

5 https://blog.twitter.com/marketing

6 https://www.statista.com/statistics higher customer service quality may attract customers to shift from conventional call centers to social media for redress seeking, especially when they perceive the overall quality through the social media channel as higher than that of traditional call centers. In such cases, prompt and effective care might encourage future complaints. Nonetheless, there is an important caveat in this mechanism. On Twitter, a conversation between a focal user and a third-party is by default displayed as truncated on a bystander's Twitter feed. Although Twitter has adopted steady improvements that help follow conversations $]^{7}$ a bystander still has to take extra steps to expand the full conversation. As such, for bystanders who do not bother to follow and read through a focal customer's service conversation, they cannot observe the service quality. Hence, the strength of this mechanism depends on the number of bystanders who actively monitor others' customer service conversations.

Based on the above arguments, we propose the following hypothesis for empirical testing:

Hypothesis 2 (H2): Ceteris paribus, higher customer service quality (i.e., faster responses and a higher resolution rate) will lead to fewer customer complaints.

\section{Data}

We collect data from Twitter as it is extensively leveraged for social media customer service ${ }^{8}$ The data include all the customer service interactions by 40 international airlines from January 2014 to September 2019, where all of these firms provide customer service regularly on Twitter. We include only customer-initiated tweets to brands, and we categorize theses voices into complaints, compliments, and informational posts using the lexicon proposed in Gunarathne et al. (2018) [3]. The data are constructed at the conversation level, with each conversation consisting of a thread initiator (i.e., customer-initiated tweet) and follow-up brand-customer communications associated with the thread. We then aggregate the conversational data to a firm-week level.

Table 1 reports the definitions of the key variables. The dependent variable is the log-transformed volume of customer-initiated complaints directed to firm $i$ at week $t\left(\log\right.$ Complaints $\left._{i, t}\right)$. We construct the measure at the conversation level so that only the thread initiator is counted. Corresponding to the hypotheses, we consider two aspects of brand service intervention as the key

${ }^{7}$ For example, Twitter has changed its interface design (see https://blog.twitter.com//.

Twitter also provided different ways of connecting conversations (see https://help.twitter.com)

${ }^{8} 80 \%$ of social media customer service requests come from Twitter according to https://blog.twitter.com/marketing/en_us/a/2016/ 
independent variables: service level and service quality. Specifically, we measure service level by the number of service interventions to customer-initiated complaints by firm $i$ at week $t$, with the logarithmic transformation $\left(\log\right.$ Replies $\left._{i, t}\right)$. We measure service quality from several aspects. Delay ${ }_{i, t}$ is the average delay in minutes from a brand's first reply to a customer-initiated complaint, which captures the timeliness of the service. We measure service effectiveness as the ratio of redress seeking conversations that end with a resolution $\left(\right.$ Resolution $\left._{i, t}\right)$. We determine the resolution for each customer complaint using a supervised classifier trained with a labeled data set from Southwest Airlines. The larger the resolution rate, the higher the service quality is. We construct an alternative measure for service effectiveness as the ratio of service encounters that end with customers' expressions of gratitude to the agents (CustomerGratitude $\left.{ }_{i, t}\right)^{9}$

In addition to the brand service level and service quality, we include various controls for average agents' response characteristics that are constructed from the conversational data. We use ReplyLength $h_{i, t}$ to measure agents' efforts in responding to complaints. Longer replies imply more effort [22]. We use ConversationLength ${ }_{i, t}$ to capture how efficient a service agent can handle a complaint. We consider firms that can address a complaint in fewer replies as more efficient. We use a lexicon-based method to check if a customer service interaction includes a direct message, and construct DirectMessage $e_{i, t}$ as the ratio of redress seeking conversations with communications in direct messages. Following Yeomans et al. (2018) [21], we further create a list of linguistic features to quantify the politeness of agents' replies, which may have direct consequences on a service intervention.

It is important to note that the brand level complaints are influenced by multiple endogenous factors. For example, if there is a shock to the customer population or brand service quality, there could be a spike in both customer voices and the brand service level. This will lead to a positive relationship between these two factors, even if there is no direct relationship. To better identify the effect of brand service level and quality, we include three variables to account for firm heterogeneity and alleviate endogeneity concerns. Specifically, we use OfflineIncidents $s_{i, t}$ and GoogleTrend ${ }_{i, t}$ to capture any offline and online shocks that could simultaneously affect customer voices and brand service strategy 10

\footnotetext{
${ }^{9} \mathrm{We}$ implement a lexicon-based method to check whether a customer explicitly appreciates the agent's efforts following [21].

${ }^{10} \mathrm{We}$ collect airlines' offline events from AeroInside https://www.aeroinside.com/incidents/category/incident, which provides detailed reports about airline incidents, accidents, and crashes.
}

We include brand Twitter followers (logFollowers $_{i, t}$ ) to proxy a firm's Twitter customer base that closely correlates with the volume of customer voices and the size of offline customers.

\section{Empirical Analysis}

In this section, we first discuss the empirical strategy and then present the empirical results on the dynamic response of customers' complaints to firms' service strategy.

\subsection{Model Specification}

To examine the effect of service intervention on the volume of customer complaints, we use the following empirical specification:

$$
\begin{aligned}
Y_{i, t}= & \beta_{1} \text { ServiceLevel }_{i, t-1}+\beta_{2} \text { ServiceQuality }_{i, t-1} \\
& +\beta_{3} X_{i, t}+\beta_{4} \text { TimeTrend }_{t}+\alpha_{i} \\
& +\delta \text { Seasonality }_{t}+\epsilon_{i, t}
\end{aligned}
$$

where $Y_{i t}$ is the log-transformed volume of customer-initiated service complaints to firm $i$ at week $t^{11}$ The key independent variables include lagged measures for service level (i.e., $\log _{\text {Replies }}$ it $_{i-1}$ ) and service quality (i.e., Delay ${ }_{i, t-1}$, Resolution R $_{i, t-1}$, and CustomerGratitude $e_{i, t-1}$ ), the structure of which precludes a potential reverse-causality explanation. Given that the data has a long panel structure with many periods for relatively few firms $(N=40, T=298$ weeks) ${ }^{12}$ we take advantage of the natural ordering of time (in weeks) and include the linear time trend to account for the platform growth. On top of various controls, we include firm fixed effects, $\alpha_{i}$, to catch unobserved time-invariant differences across brands. We also control for seasonality effects through year and month dummies, which capture the unobserved shocks in customer voicing decisions and brand reply strategies.

A major concern for long-panel data is that error terms may not be independent and identically distributed. The failure to correct for serial correlation of errors, if present, can cause the standard errors of the estimates to be smaller compared with their actual value, thus leading to incorrect tests of hypotheses [23]. As a first step, we refer to the Wooldridge test, and

\footnotetext{
${ }^{11}$ Since the raw volume measures are highly skewed within and across firms, the log-transformed measures enable better interpretation and easier comparison of the estimates across firms.

${ }^{12}$ Note. Some firms have a shorter time window due to missing data. For example, Virgin America was integrated into Alaska Airlines on April 24, 2018. Jet Airways ceased all flight operations in April 2019. We exclude those observations from the analysis.
} 
the result rejects the null hypothesis that there is no serial correlation in the residuals of the fixed effects model $(F(1,39)=171.329, p<0.01)[24,25]$. To account for the autocorrelation in the disturbance term, we specify the error term, $\epsilon_{i, t}$, as autoregressive with order one AR(1) ${ }^{13}$

$$
\epsilon_{i, t}=\rho \epsilon_{i, t-1}+\eta_{i, t}
$$

where $|\rho|<1$ and $\eta_{i, t}$ is independent and identically distributed [29]. The AR(1) error structure captures persistence in customers' and brands' behaviors, for example, word-of-mouth among customers, growth of brands' online social networks, evolution in the social media service labor, etc.

\subsection{Baseline Result}

Table 2 reports the estimation results on the dynamics of brand service and customer complaints following specification (1) in Section 5.1. Take column (1) as an example, the coefficient estimates for service level (logReplies $\left.{ }_{i, t-1}\right)$ are positively significant, supporting the H1, which states that a higher service level leads to more customer complaints in the following period. In terms of magnitude, a one percent increase in the service level leads to about a $0.13 \%$ increase in customer complaints. Regarding service quality measures, we find a positive coefficient estimate for Delay $_{i, t-1}$ and a negative coefficient estimate for Resolution $_{i, t-1}$. The results suggest that slower responses can incur more future complaints, while better resolution can reduce future complaints. Both findings support H2. More specifically, a one percent delay in brands' first responses to service complaints associates with a $0.01 \%$ increase in future complaints, and a one percent increase in resolution rate associates with a $0.08 \%$ reduction in future complaints.

As mentioned in Section 4, customers' voicing decisions are influenced by multiple factors that are likely endogenous, which makes it necessary to control for offline service shocks and online customer growth. From the regression analysis, we observe expected coefficient estimates of key brand controls. For example, shocks to both offline and online performance correlate with more future complaints. The increasing number of brand followers also explains a large proportion of the increasing volume of customer complaints.

\footnotetext{
${ }^{13}$ We implement the analysis using STATA procedure XTREGAR [26. 27]. All the results remain robust when imposing panel-specific AR(1) disturbance. Results are available upon request. However, since [28] (p. 638) recommend against estimating panel-specific AR parameters, as opposed to one AR parameter for all panels, we report results assuming common $\mathrm{AR}(1)$ disturbance across panels in the current paper.
}

Considering that firms may have nonlinear growth patterns in the social media customer service provision, we further impose a quadratic time trend in column (2). Our main findings remain robust. In columns (3) - (4), we replace Resolution $_{i, t-1}$ with the alternative measure, CustomerGratitude ${ }_{i, t-1}$, for service effectiveness. Under different specifications, the estimates remain qualitatively the same, demonstrating the robustness of the results.

\subsection{Instrumental Variable Analysis}

Despite a wide range of controls, a remaining threat to our identification strategy is unobserved, time-varying factors that affect the sensitivity of customer complaints to brand service efforts. To alleviate the concern that the findings may be driven by spurious correlation rather than causality, we apply an instrumental variable (IV) analysis in this section. Specifically, we construct the instrumental variable $\Delta$ NeuVoice $_{i, t-1}$ for logReplies lit-1 $_{1}$, which represents the lagged changes in the composition of customer voices directed to firm $i$ :

$$
\text { NeuRatio }_{i, t}=\frac{\text { Neutral Customer Voices }}{i, t}
$$

$$
\Delta \text { NeuVoice }_{i, t-1}=\text { NeuRatio }_{i, t-1}-\text { NeuRatio }_{i, t-2}
$$

The underlying assumption is that $\Delta$ NeuVoice $_{i, t-1}$ affects customer complaints (log Complaints Con $_{i, t}$ ) only through brand service level (logReplies ${ }_{i, t-1}$ ). The logic is as follows: given the limited servers (i.e., number of agents), any shocks from the demand side requests (i.e., customer voices composition) will lead to the re-allocation of agent resources (i.e., brand replies to customer voices of different types). Since $\Delta N$ euV oice ${ }_{i, t-1}$ reflects the changes in neutral voices, it shall directly affect the level of brand replies to complaints $\left(\log\right.$ Replies $\left._{i, t}\right)$. In the meantime, as neutral voices correspond to informational inquiries, they are unlikely to affect future customer complaints.

The F-test and Stock-Yogo weak IV test indicate the strong relevance of IV to the endogenous variable. Table 3 reports the estimation results. As expected, the estimate for the IV is significantly negative in the first stage, suggesting that an increase in customers' neutral voices (i.e., informational inquiries) negatively affects a firm's resources allocated to complaints (logReplies $i_{i, t}$ ). In the second stage, the coefficient estimates of the service level and service quality are consistent with the baseline results, reconfirming the robustness of the findings. 


\section{Mechanism Test on Service Awareness}

Online social ties can affect individuals' behaviors from various aspects, such as the diffusion of YouTube videos [30], peer music consumption [31], and the participation in charitable social movements [32]. Similarly, online social ties can affect customer complaining behavior in the context of social media customer service. Each time a firm responds to a service inquiry on social media, customers who are connected to the focal redress-seeking customer can observe the service intervention. Previous literature shows that customers are more likely to seek redress if it is clear that the seller is willing to remedy the problem [19]. Further, customers who enter a complaint situation, knowing how fellow customers have been treated in similar circumstances, are likely to expect similar treatment [18]. Accordingly, brands' active service responses combined with customers' social ties will enhance the overall awareness of firms' service availability, thereby driving more customers to seek redress via social media.

To empirically test this "awareness enhancement" effect, we take advantage of an obscure technological nuance of Twitter. When a user posts a tweet directed at a firm's Twitter account, the probability that her tweet will appear in her followers' home timeline depends on the position of the @ symbol. Specifically, a mention is a tweet that contains another account's Twitter username, preceded by the "@” symbol. If a customer posts a complaint in such format, "I need help with ... @Delta ...", anyone on Twitter who is following the customer will see the tweet in their home timeline. A reply is a tweet that starts with the "@username". If a customer posts a complaint in this format, “@Delta. I need help with ...", only those who follow both the customer and Delta will see such tweets in their home timeline. Since the awareness effect depends on the number of potential viewers of a redress seeking tweet, we construct two service awareness measures at the firm-week level, taking into account of different levels of publicity:

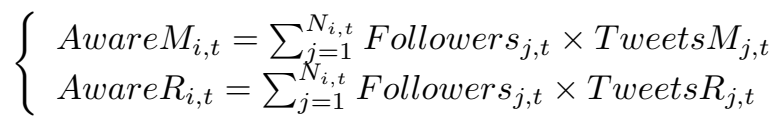

where Followers $j_{j, t}$ measures the number of followers of customer $j$ at week $t$, Tweets $M_{j, t}$ and Tweets $R_{j, t}$ correspond to the number of customer $j$ 's initiated complaints (that get replied by firm $i$ ) in the form of mention and reply. $N_{i, t}$ is the number of unique users who complained to firm $i$ in week $t$. If the service awareness mechanism does exist, we shall expect to see a larger effect through AwareM $_{i, t}$ because such service interactions are directly visible to all potential audiences and can inform them of the existence of the new service channel.

The marketing literature has documented that for memory decay and related reasons, past advertising may not be as effective as recent advertising [33]. Similarly, potential customers' awareness through friends' usage of social media customer service may decay over time. Accordingly, we construct the service awareness stock to measure the cumulative customer's knowledge of firm $i$ 's service availability on Twitter up to time $t$ as follows:

$\left\{\begin{array}{l}\text { AwareStock }_{i, t}=\delta \text { AwareStock } M_{i, t-1}+\text { Aware }_{i, t} \\ \text { AwareStock }_{i, t}=\delta \text { AwareStock } R_{i, t-1}+\text { Aware }_{i, t}\end{array}\right.$

where $\delta$ is the parameter for memory attrition overtime and $\delta \in(0,1)$. The awareness stock depends on both the last period brand awareness stock and the service awareness in the current period. Table 4 reports the regression results when $\delta=0.1$, which corresponds to the regression model with the lowest AIC and BIC, and the highest log-likelihood. Although the coefficients for both awareness measures are positive, only the coefficient estimates for AwareStockM ${ }_{i, t}$ are consistently significant throughout different specifications. The findings support the awareness enhancement mechanism, implying that increasing awareness of firms' service availability through higher service efforts is an underlying driver for the increasing volume of customer complaints.

\section{Discussion and Conclusion}

Social media has become a promising alternative to traditional call centers because of its low handling costs and potential positive amplification effect. However, due to the easy access and low voicing costs, firms may worry about chronic complainers who use the channel excessively. A recent study [4] also suggests that brand interventions on social media encourage more subsequent complaints from individual customers. In such cases, firms worry that active management of customer requests may do more harm than good. The current paper clarifies this pressing concern by examining the dynamics between service intervention and the brand-level customer complaining behavior. Using a large data set with all the customer-brand service interactions of 40 international airlines over almost six years on Twitter, we find that a higher service level will cause more customer complaints on social media. More importantly, such an increase is primarily driven by the awareness enhancement effect. Particularly, customers who are connected to focal complainers become aware of social media customer 
service and are more likely to use it in the future. Furthermore, we find that higher customer service quality (i.e., prompt responses and a higher resolution rate) will lead to fewer customer complaints.

This paper contributes to the information systems and marketing literature in the following aspects. First, while previous research examines the effect of service intervention as a binary treatment on the voicing decisions of a limited sample of customers [4], we rely on a large panel data set and conduct a more granular analysis utilizing the rich textual information from the customer-brand conversations. We conduct a brand-level analysis and identify the causal impact of service intervention adjusting for various confounding factors, including customer population, service quality, online and offline shocks to a brand. We believe the drastic difference in data and empirical strategies advances the nascent literature on the relationship between brand service intervention and customer voices on social media. Second, While Ma et al. (2015) suggested that service intervention increases an individual's tendency to complain, our findings demonstrate that the awareness enhancement mechanism is a primary driver for the increasing customer complaints to a brand. We believe such knowledge is crucial to researchers and practitioners who worry about the risk of abusive use of the channel by disgruntled customers.

Our findings also provide valuable insights to practitioners. Besides addressing a focal customer's complaint, active service intervention also enhances bystanders' awareness of the social media customer service and redirect them to this cost-effective channel. Following Hirschman's (1970) Theory of Exit, Voice, and Loyalty, when a customer becomes dissatisfied with the services or products provided by the firms, she chooses either to exit or to voice. In other words, active customer service management can potentially improve customer retention, as those who would otherwise exit the business can now easily tweet to a brand. The feature of low voicing cost provides firms with a precious opportunity to collect customer feedback, rectify offline service failure, and prevent customer churn in the long run. Hence, firms should embrace social media customer service and implement a more active, prompt, and effective strategy.

Our work has several limitations that bear noting and offer opportunities for future research. First, although Twitter is the dominating platform that enables firms for customer service provision, a further extension of our study is to conduct similar research on different social media platforms, such as Facebook. As customers on those platforms can be different from those on Twitter, it would be interesting to check if there is any variation in the findings and mechanisms. Second, although the airline industry is an essential service sector and has leveraged social media extensively for customer service provision, future works may examine the external validity using data from other service sectors.

\section{References}

[1] N. Huang, T. Sun, P. Chen, and J. M. Golden, "Word-of-mouth system implementation and customer conversion: A randomized field experiment," Information Systems Research, vol. 30, no. 3, pp. 805-818, 2019.

[2] R. Ahluwalia, R. E. Burnkrant, and H. R. Unnava, "Consumer response to negative publicity: The moderating role of commitment," Journal of Marketing Research, vol. 37, no. 2, pp. 203-214, 2000.

[3] P. Gunarathne, H. Rui, and A. Seidmann, "When social media delivers customer service: Differential customer treatment in the airline industry," MIS Quarterly, vol. 42, no. 2, pp. 489-520, 2018.

[4] L. Ma, B. Sun, and S. Kekre, "The squeaky wheel gets the grease-an empirical analysis of customer voice and firm intervention on twitter," Marketing Science, vol. 34, no. 5, pp. 627-645, 2015.

[5] A. O. Hirschman, Exit, voice, and loyalty: Responses to decline in firms, organizations, and states, vol. 25. Harvard university press, 1970.

[6] A. Kumar and R. Telang, "Does the web reduce customer service cost? empirical evidence from a call center," Information Systems Research, vol. 23, no. 3-part-1, pp. 721-737, 2012.

[7] Y. Hu, A. Tafti, and D. Gal, "Read this, please? The role of politeness in customer service engagement on social media," in Proceedings of the 52nd Hawaii International Conference on System Sciences, 2019.

[8] T. Hennig-Thurau, K. P. Gwinner, G. Walsh, and D. D. Gremler, "Electronic word-of-mouth via consumer-opinion platforms: what motivates consumers to articulate themselves on the internet?," Journal of Interactive Marketing, vol. 18, no. 1, pp. 38-52, 2004.

[9] O. Toubia and A. T. Stephen, "Intrinsic vs. image-related utility in social media: Why do people contribute content to twitter?," Marketing Science, vol. 32, no. 3, pp. 368-392, 2013.

[10] J. Berger and E. M. Schwartz, "What drives immediate and ongoing word of mouth?," Journal of Marketing Research, vol. 48, no. 5, pp. 869-880, 2011.

[11] M. J. Lovett, R. Peres, and R. Shachar, "On brands and word of mouth," Journal of Marketing Research, vol. 50, no. 4, pp. 427-444, 2013.

[12] B. Gu and Q. Ye, "First step in social media: Measuring the influence of online management responses on customer satisfaction," Production and Operations Management, vol. 23, no. 4, pp. 570-582, 2014.

[13] D. Proserpio and G. Zervas, "Online reputation management: Estimating the impact of management responses on consumer reviews," Marketing Science, vol. 36, no. 5, pp. 645-665, 2017. 
[14] Y. Wang and A. Chaudhry, "When and how managers' responses to online reviews affect subsequent reviews," Journal of Marketing Research, vol. 55, no. 2, pp. 163-177, 2018.

[15] C. Yi, Z. Jiang, X. Li, and X. Lu, "Leveraging user-generated content for product promotion: The effects of firm-highlighted reviews," Information Systems Research, vol. 30, no. 3, pp. 711-725, 2019.

[16] M. Yang, Z. Zheng, and V. Mookerjee, "Prescribing response strategies to manage customer opinions: A stochastic differential equation approach," Information Systems Research, vol. 30, no. 2, pp. 351-374, 2019.

[17] R. Mousavi, M. Johar, and V. S. Mookerjee, "The voice of the customer: Managing customer care in twitter," Information Systems Research, 2020.

[18] S. S. Tax, S. W. Brown, and M. Chandrashekaran, "Customer evaluations of service complaint experiences: implications for relationship marketing," Journal of Marketing, vol. 62, no. 2, pp. 60-76, 1998 .

[19] J. G. Blodgett, K. L. Wakefield, and J. H. Barnes, "The effects of customer service on consumer complaining behavior," Journal of Services Marketing, 1995.

[20] J. P. Melancon and V. Dalakas, "Consumer social voice in the age of social media: Segmentation profiles and relationship marketing strategies," Business Horizons, vol. 61, no. 1, pp. 157-167, 2018.

[21] M. Yeomans, A. Kantor, and D. Tingley, "The politeness package: Detecting politeness in natural language.," $R$ Journal, vol. 10, no. 2, 2018.

[22] J. A. Chevalier, Y. Dover, and D. Mayzlin, "Channels of impact: User reviews when quality is dynamic and managers respond," Marketing Science, vol. 37, no. 5, pp. 688-709, 2018.

[23] A. Bhargava, L. Franzini, and W. Narendranathan, "Serial correlation and the fixed effects model," The Review of Economic Studies, vol. 49, no. 4, pp. 533-549, 1982.

[24] J. M. Wooldridge, "Econometric analysis of cross section and panel data mit press," Cambridge, MA, vol. 108, 2002.

[25] D. M. Drukker, "Testing for serial correlation in linear panel-data models," The stata journal, vol. 3, no. 2, pp. 168-177, 2003.

[26] D. Hoechle, "Robust standard errors for panel regressions with cross-sectional dependence," The Stata Journal, vol. 7, no. 3, pp. 281-312, 2007.

[27] A. C. Cameron and P. K. Trivedi, "Microeconometrics using stata," Indicator, vol. 2, p. 47, 2009.

[28] N. Beck and J. N. Katz, "What to do (and not to do) with time-series cross-section data," American Political Science Review, vol. 89, no. 3, pp. 634-647, 1995.

[29] B. H. Baltagi and P. X. Wu, "Unequally spaced panel data regressions with ar (1) disturbances," Econometric Theory, vol. 15, no. 6, pp. 814-823, 1999.

[30] A. Susarla, J.-H. Oh, and Y. Tan, "Social networks and the diffusion of user-generated content: Evidence from youtube," Information Systems Research, vol. 23, no. 1, pp. 23-41, 2012

[31] S. Dewan, Y.-J. Ho, and J. Ramaprasad, "Popularity or proximity: Characterizing the nature of social influence in an online music community," Information Systems Research, vol. 28, no. 1, pp. 117-136, 2017.
[32] X. Tan, Y. Lu, and Y. Tan, "The impact of subscription reciprocity on charitable content creation and sharing: Evidence from twitter on giving tuesday," MIS Quarterly, Forthcoming, 2020.

[33] P. A. Naik, M. K. Mantrala, and A. G. Sawyer, "Planning media schedules in the presence of dynamic advertising quality," Marketing Science, vol. 17, no. 3, pp. 214-235, 1998.

Table 1: Variable Definition

\begin{tabular}{|c|c|}
\hline Variable & Definition \\
\hline & Customer Voice \\
\hline logComplaints & Customer complaints volume (log-scale) \\
\hline \multirow[t]{2}{*}{ NeuRatio } & Percentage $(\%)$ of neutral customer voices \\
\hline & Brand Service Strategy \\
\hline \multicolumn{2}{|l|}{ Service Level } \\
\hline logReplies & $\begin{array}{l}\text { Number of brand service interventions to } \\
\text { customer-initiated complaints (log-scale) }\end{array}$ \\
\hline \multicolumn{2}{|l|}{ Service Quality } \\
\hline Delay & $\begin{array}{l}\text { Time (in minutes) from a brand's first reply } \\
\text { to customer-initiated complaints (log-scale) }\end{array}$ \\
\hline Resolution & $\begin{array}{l}\text { Ratio of redress seeking conversations } \\
\text { ended with a resolution }\end{array}$ \\
\hline CustomerGratitude & $\begin{array}{l}\text { Ratio of redress seeking conversations with } \\
\text { customers expressing their gratitude to agents }\end{array}$ \\
\hline \multicolumn{2}{|l|}{ Other Controls } \\
\hline ReplyLength & \# of words per brand reply \\
\hline ConversationLength & \# of brand replies per service intervention \\
\hline DirectMessage & $\begin{array}{l}\text { Ratio of redress seeking conversations } \\
\text { with direct messages }\end{array}$ \\
\hline Please & Ratio of agents' usage of "please" \\
\hline Apology & Ratio of agents' apology to customers \\
\hline Reasoning & $\begin{array}{l}\text { Ratio of agents' explicit reference to } \\
\text { reasons }\end{array}$ \\
\hline Reassurance & $\begin{array}{l}\text { Ratio of agents' efforts to minimize } \\
\text { customers' concerns }\end{array}$ \\
\hline Gratitude & $\begin{array}{l}\text { Ratio of agents' expressing appreciation } \\
\text { to customers in replies }\end{array}$ \\
\hline \multirow{3}{*}{$\begin{array}{l}\text { OfflineIncidents } \\
\text { GoogleTrend } \\
\text { logFollowers }\end{array}$} & Brand Control \\
\hline & $\begin{array}{l}\text { Number of brands' offline incidents } \\
\text { Google search volume index for a brand } \\
\text { \# of brand's Twitter followers (log-scale) }\end{array}$ \\
\hline & Service Awareness \\
\hline \multirow[t]{2}{*}{ AwareStockR } & $\begin{array}{l}\text { Cumulative awareness via mentions (log-scale) } \\
\text { Cumulative awareness via replies (log-scale) }\end{array}$ \\
\hline & Instrumental Variable \\
\hline$\Delta$ NeuVoice & Changes in neutral customer voices (in \%) \\
\hline
\end{tabular}


Table 2: Customer Complaints and Brand Service Intervention

\begin{tabular}{|c|c|c|c|c|}
\hline & \multicolumn{4}{|c|}{ DV: logComplaints Cot $_{i t}$} \\
\hline & (1) & $(2)$ & (3) & (4) \\
\hline $\begin{array}{l}\text { Service Level } \\
\log _{\text {Replies }}, t-1\end{array}$ & $\begin{array}{c}0.132 * * * \\
(0.008)\end{array}$ & $\begin{array}{c}0.137 * * * \\
(0.008)\end{array}$ & $\begin{array}{c}0.125 * * * \\
(0.008)\end{array}$ & $\begin{array}{c}0.130 * * * \\
(0.008)\end{array}$ \\
\hline $\begin{array}{l}\text { Service Quality } \\
\text { Delay }_{i, t-1}\end{array}$ & $\begin{array}{c}0.013 * * * \\
(0.004)\end{array}$ & $\begin{array}{c}0.012 * * * \\
(0.004)\end{array}$ & $\begin{array}{c}0.013 * * * \\
(0.004)\end{array}$ & $\begin{array}{c}0.012 * * * \\
(0.004)\end{array}$ \\
\hline Resolution $_{i, t-1}$ & $\begin{array}{c}-0.081 * * * \\
(0.017)\end{array}$ & $\begin{array}{c}-0.082 * * * \\
(0.017)\end{array}$ & & \\
\hline CustomerGratitude $_{i, t-1}$ & & & $\begin{array}{c}-0.092 * * \\
(0.040)\end{array}$ & $\begin{array}{c}-0.094 * * \\
(0.040)\end{array}$ \\
\hline $\begin{array}{l}\text { Brand Control } \\
\text { OfflineIncidents } \\
i, t\end{array}$ & $\begin{array}{c}0.045 * * * \\
(0.008)\end{array}$ & $\begin{array}{c}0.045^{* * * *} \\
(0.008)\end{array}$ & $\begin{array}{c}0.045 * * * \\
(0.008)\end{array}$ & $\begin{array}{c}0.045^{* * * *} \\
(0.008)\end{array}$ \\
\hline GoogleTrend $_{i, t}$ & $\begin{array}{c}0.005 * * * \\
(0.0004)\end{array}$ & $\begin{array}{c}0.005^{* * * *} \\
(0.0004)\end{array}$ & $\begin{array}{c}0.005 * * * \\
(0.0004)\end{array}$ & $\begin{array}{c}0.005^{* * * *} \\
(0.0004)\end{array}$ \\
\hline logFollowers $_{i, t}$ & $\begin{array}{c}0.272 * * * \\
(0.024)\end{array}$ & $\begin{array}{c}0.217 * * * \\
(0.028)\end{array}$ & $\begin{array}{c}0.273 * * * \\
(0.024)\end{array}$ & $\begin{array}{c}0.218^{* * * *} \\
(0.028)\end{array}$ \\
\hline Other Controls & Y & Y & Y & $\mathrm{Y}$ \\
\hline Linear Time Trend & Y & Y & Y & $\mathrm{Y}$ \\
\hline Quadratic Time Trend & $\mathrm{N}$ & Y & $\mathrm{N}$ & $\mathrm{Y}$ \\
\hline Firm \& Year \& Month FE & $\mathrm{Y}$ & $\mathrm{Y}$ & $\mathrm{Y}$ & $\mathrm{Y}$ \\
\hline$R^{2}$ & 0.156 & 0.158 & 0.152 & 0.155 \\
\hline$\rho_{a r}$ & 0.302 & 0.298 & 0.307 & 0.302 \\
\hline Observations & 11544 & 11544 & 11544 & 11544 \\
\hline
\end{tabular}

Table 3: Instrumental Variable Analysis

\begin{tabular}{|c|c|c|c|c|}
\hline & \multicolumn{4}{|c|}{ DV: logComplaints ${ }_{i, t}$} \\
\hline & (1) & (2) & (3) & (4) \\
\hline $\begin{array}{l}\text { Service Level } \\
\text { logReplies }_{i, t-1}\end{array}$ & $\begin{array}{c}0.157 * * \\
(0.071)\end{array}$ & $\begin{array}{c}0.157 * * \\
(0.070)\end{array}$ & $\begin{array}{c}0.153^{* *} \\
(0.070)\end{array}$ & $\begin{array}{c}0.153 * * \\
(0.070)\end{array}$ \\
\hline $\begin{array}{l}\text { Service Quality } \\
\text { Delay }_{i, t-1}\end{array}$ & $\begin{array}{c}0.032 * * * \\
(0.005)\end{array}$ & $\begin{array}{l}0.030^{* * *} * \\
(0.005)\end{array}$ & $\begin{array}{c}0.031^{* * *} * \\
(0.005)\end{array}$ & $\begin{array}{l}0.030 * * * \\
(0.005)\end{array}$ \\
\hline Resolution $_{i, t-1}$ & $\begin{array}{l}-0.103 * * * \\
(0.027)\end{array}$ & $\begin{array}{l}-0.102 * * * \\
(0.027)\end{array}$ & & \\
\hline CustomerGratitude $_{i, t-1}$ & & & $\begin{array}{c}-0.119 * * \\
(0.052)\end{array}$ & $\begin{array}{c}-0.122 * * \\
(0.051)\end{array}$ \\
\hline $\begin{array}{l}\text { Brand Control } \\
\text { OfflineIncidents } s_{i, t}\end{array}$ & $\begin{array}{c}0.064 * * * \\
(0.009)\end{array}$ & $\begin{array}{c}0.064 * * * \\
(0.009)\end{array}$ & $\begin{array}{c}0.065 * * * \\
(0.009)\end{array}$ & $\begin{array}{c}0.064 * * * * \\
(0.009)\end{array}$ \\
\hline GoogleTrend $_{i, t}$ & $\begin{array}{c}0.004 * * * \\
(0.001)\end{array}$ & $\begin{array}{c}0.004 * * * \\
(0.001)\end{array}$ & $\begin{array}{c}0.004 * * * \\
(0.001)\end{array}$ & $\begin{array}{c}0.004 * * * \\
(0.001)\end{array}$ \\
\hline $\operatorname{logFollowers}_{i, t}$ & $\begin{array}{c}0.301 * * * \\
(0.040)\end{array}$ & $\begin{array}{c}0.254 * * * \\
(0.053)\end{array}$ & $\begin{array}{c}0.300^{* * * *} \\
(0.040)\end{array}$ & $\begin{array}{c}0.253 * * * * \\
(0.053)\end{array}$ \\
\hline $\begin{array}{l}\text { 1st-stage Results } \\
\Delta N \text { euV oice }{ }_{i, t-1}\end{array}$ & $\begin{array}{l}-0.008 * * * \\
(0.0008)\end{array}$ & $\begin{array}{c}-0.008 * * * \\
(0.0008)\end{array}$ & $\begin{array}{c}-0.009^{* * *} \\
(0.0008)\end{array}$ & $\begin{array}{c}-0.009 * * * \\
(0.0008)\end{array}$ \\
\hline $\begin{array}{l}\text { Other Controls } \\
\text { Linear Time Trend } \\
\text { Quadratic Time Trend } \\
\text { Firm \& Year \& Month FE }\end{array}$ & $\begin{array}{l}\mathrm{Y} \\
\mathrm{Y} \\
\mathrm{N} \\
\mathrm{Y}\end{array}$ & $\begin{array}{l}\mathrm{Y} \\
\mathrm{Y} \\
\mathrm{Y} \\
\mathrm{Y}\end{array}$ & $\begin{array}{l}\mathrm{Y} \\
\mathrm{Y} \\
\mathrm{N} \\
\mathrm{Y}\end{array}$ & $\begin{array}{l}\mathrm{Y} \\
\mathrm{Y} \\
\mathrm{Y} \\
\mathrm{Y}\end{array}$ \\
\hline $\begin{array}{l}R^{2} \\
\text { Observations }\end{array}$ & $\begin{array}{l}0.275 \\
11544 \\
\end{array}$ & $\begin{array}{l}0.276 \\
11544 \\
\end{array}$ & $\begin{array}{l}0.272 \\
11544\end{array}$ & $\begin{array}{l}0.273 \\
11544 \\
\end{array}$ \\
\hline
\end{tabular}

Figure 1: Average Daily Complaint Volume per Firm on Twitter Over Time

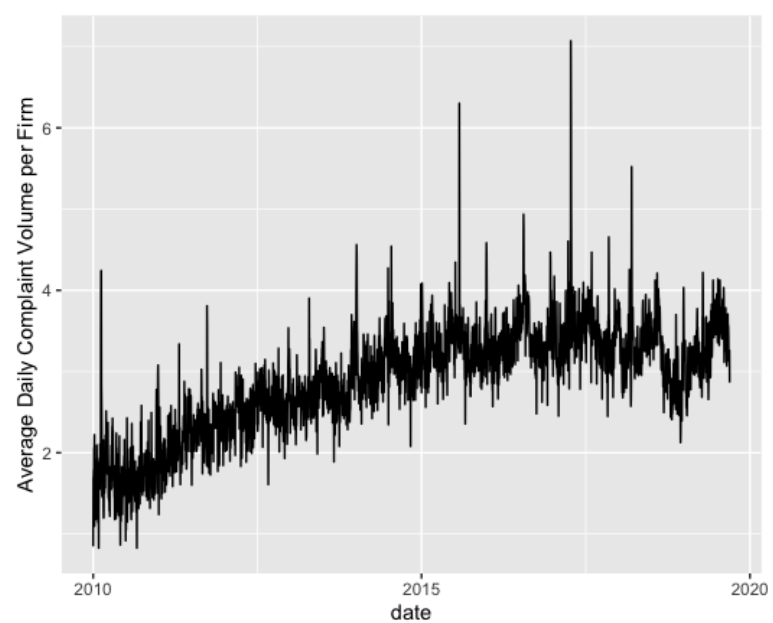

Note. This figure plots the average volume of customer-initiated complaints per firm/day on Twitter over time (the Y-axis is in $\log$-scale).
Table 4: Mechanism Test on Service Awareness

\begin{tabular}{|c|c|c|c|c|}
\hline & \multicolumn{4}{|c|}{ DV: $\log$ Complaints $s_{i, t}$} \\
\hline & (1) & (2) & (3) & (4) \\
\hline $\begin{array}{l}\text { Awareness Stock } \\
\text { AwareStock }_{i, t-1}\end{array}$ & $\begin{array}{c}0.0063 * * * \\
(0.0023)\end{array}$ & $\begin{array}{c}0.0064 * * * * \\
(0.0023)\end{array}$ & $\begin{array}{c}0.0061 * * * \\
(0.0023)\end{array}$ & $\begin{array}{c}0.0061 * * * \\
(0.0023)\end{array}$ \\
\hline AwareStock $R_{i, t-1}$ & $\begin{array}{c}0.0016 \\
(0.0027)\end{array}$ & $\begin{array}{c}0.0015 \\
(0.0027)\end{array}$ & $\begin{array}{c}0.0009 \\
(0.0027)\end{array}$ & $\begin{array}{c}0.0008 \\
(0.0026)\end{array}$ \\
\hline $\begin{array}{l}\text { Service Quality } \\
\text { Delay }_{i, t-1}\end{array}$ & $\begin{array}{c}0.0059 \\
(0.0039)\end{array}$ & $\begin{array}{c}0.0051 \\
(0.0039)\end{array}$ & $\begin{array}{c}0.0059 \\
(0.0039)\end{array}$ & $\begin{array}{c}0.0051 \\
(0.0039)\end{array}$ \\
\hline Resolution $_{i, t-1}$ & $\begin{array}{c}-0.0457 * * * \\
(0.0159)\end{array}$ & $\begin{array}{c}-0.0455^{* * * *} \\
(0.0159)\end{array}$ & & \\
\hline CustomerGratitude $_{i, t-1}$ & & & $\begin{array}{c}-0.0749 * * \\
(0.0378)\end{array}$ & $\begin{array}{c}-0.0755^{* *} \\
(0.0378)\end{array}$ \\
\hline $\begin{array}{l}\text { Brand Control } \\
\text { OfflineIncidents } s_{i, t}\end{array}$ & $\begin{array}{c}0.0371 * * * \\
(0.0072)\end{array}$ & $\begin{array}{c}0.0369 * * * \\
(0.0072)\end{array}$ & $\begin{array}{c}0.0371 * * * \\
(0.0072)\end{array}$ & $\begin{array}{c}0.0369 * * * \\
(0.0072)\end{array}$ \\
\hline GoogleTrend $_{i, t}$ & $\begin{array}{c}0.0067 * * * \\
(0.0005)\end{array}$ & $\begin{array}{c}0.0067 * * * \\
(0.0005)\end{array}$ & $\begin{array}{c}0.0068 * * * \\
(0.0005)\end{array}$ & $\begin{array}{c}0.0068^{* * *} * \\
(0.0005)\end{array}$ \\
\hline logFollowers $_{i, t}$ & $\begin{array}{c}0.2752 * * * \\
(0.0279)\end{array}$ & $\begin{array}{c}0.2319 * * * \\
(0.0320)\end{array}$ & $\begin{array}{c}0.2761 * * * * \\
(0.0280)\end{array}$ & $\begin{array}{c}0.2323 * * * \\
(0.0321)\end{array}$ \\
\hline Other Controls & $\mathrm{Y}$ & Y & $\mathrm{Y}$ & Y \\
\hline Linear Time Trend & $\mathrm{Y}$ & $\mathrm{Y}$ & $\mathrm{Y}$ & $\mathrm{Y}$ \\
\hline Quadratic Time Trend & $\mathrm{N}$ & $\mathrm{Y}$ & $\mathrm{N}$ & Y \\
\hline Firm \& Year \& Month FE & $\mathrm{Y}$ & $\mathrm{Y}$ & $\mathrm{Y}$ & $\mathrm{Y}$ \\
\hline$R^{2}$ & 0.1051 & 0.1057 & 0.1043 & 0.1049 \\
\hline$\rho_{a r}$ & 0.4586 & 0.4587 & 0.4607 & 0.4608 \\
\hline Observations & 11544 & 11544 & 11544 & 11544 \\
\hline
\end{tabular}

